\title{
Education and Civil Conflict in Nepal
}

\author{
Christine Valente
}

Between 1996 and 2006, Nepal experienced violent civil conflict as a consequence of a Maoist insurgency, which many argue also brought about an increase in female empowerment. This paper exploits variations in exposure to conflict by birth cohort, survey date, and district to estimate the impact of the insurgency on education outcomes. Overall conflict intensity, measured by conflict casualties, is associated with an increase in female educational attainment, whereas abductions by Maoists, which often targeted school children, have the reverse effect. Male schooling tended to increase more rapidly in areas where the fighting was more intense, but the estimates are smaller in magnitude and more sensitive to specification than estimates for females. Similar results are obtained across different specifications, and robustness checks indicate that these findings are not due to selective migration. JEL codes: I20, J12, O12

Between 1996 and 2006, Nepal experienced violent civil conflict as a consequence of a Maoist insurgency. This paper investigates the impact of being exposed to this insurgency at a young age on education outcomes.

This study makes both an empirical and a methodological contribution to the growing literature on the impact of civil conflict on human capital formation. First, this paper extends our understanding of the impact of civil conflict on education to include a conflict of moderate intensity. With just over 13,000 casualties and less than 1 percent of the population forcibly displaced, the level of violence considered in this study was much lower than in conflict episodes considered in previous research. ${ }^{1}$ Second, two alternative identification strategies

Christine Valente is a Lecturer (Assistant Professor) at the University of Bristol, United Kingdom; her email address is christine.valente@bristol.ac.uk. The author thanks INSEC for sharing their conflict data and Martha Ainsworth, Quy-Toan Do, Helge Holterman, Steve McIntosh, Gudrun Østby, Kati Schindler, Olga Shemyakina, Helen Simpson, Sarah Smith, Frank Windmeijer, Hassan Zaman, the World Bank's Nepal Country Director's office, and participants at two Gender and Conflict Research Workshops at the World Bank (Washington) and Peace Research Institute Oslo for their useful comments. The author also thanks three anonymous referees for their valuable comments and suggestions. This work was supported by the World Bank-Norway Trust Fund. The views expressed in this paper are those of the author alone and do not necessarily reflect those of the funding agencies. A supplemental appendix to this article is available at http://wber.oxfordjournals.org/.

1. The estimated number of individuals forcibly displaced in Nepal is approximately 200,000 (USAID, 2007). Studies reviewed in this paper have considered the impact of conflict on education in Tajikistan (between 50,000 and 100,000 deaths and 10 percent of the country's population internally displaced in the two worst years of conflict, Shemyakina, 2011b), Guatemala (200,000 deaths during the worst conflict period, Chamarbagwala and Morán, 2011), Rwanda (nearly 10 percent of the population killed, Akresh and de Walque, 2008), and Peru (just under 70,000 deaths, León 2012).

THE WORLD BANK ECONOMIC REVIEW, VOL. 28, NO. 2, pp. 354-383

doi:10.1093/wber/lht014

Advance Access Publication June 3, 2013

(C) The Author 2013. Published by Oxford University Press on behalf of the International Bank for Reconstruction and Development / THE WORLD BANK. All rights reserved. For permissions, please e-mail: journals.permissions@oup.com 
are employed to increase confidence in the reliability of the estimates: the first relies on variation in conflict exposure across birth cohorts and geographic areas in a single survey, as is standard in the literature (e.g., Akresh and de Walque 2008; Shemyakina 2011a; Chamarbagwala and Morán 2011), and the second relies on variation in exposure to conflict among school-aged individuals between household surveys and geographic areas.

Educational attainment is generally expected to be adversely affected by exposure to armed civil conflict. Direct youth enrollment in the military, limited mobility, and the destruction of schools may all negatively affect the ability of children to attend school. Increased poverty may drive parents to remove children from school (to avoid direct costs) and put them to work (to avoid opportunity costs). Political instability and reduced life expectancy may decrease expected returns to education and, in turn, reduce investments in human capital. Moreover, the schooling of girls is often more sensitive to worsening economic conditions than that of boys. A conflict environment may also hinder the functioning of education programs by weakening government institutions and imposing logistical and staff security challenges on local and international NGOs.

However, the general expectation that schooling is disrupted in conflict areas may not be well founded in the particular case of Nepal. National trends do not indicate an increase in poverty coinciding with the conflict but rather a steady decline in poverty (World Bank 2005). Despite difficulties with public service provision, basic health and education services have been maintained (Armon et al. 2004). In addition, the insurgency may have had a positive effect on schooling outcomes despite the fighting through both intended and unintended consequences of the Maoist presence. The insurgents have been reported to police teacher absenteeism (Hart 2001; see also Collins 2006 and Devkota and van Teijlingen 2010, for a similar argument regarding health workers) and have explicitly opposed caste- and ethnicity-biased traditions; these actions may have directly benefited both male and female education. In addition, the insurgents have publicly opposed gender inequality, including gender inequality in access to schooling. For instance, it has been reported that "the Maoists have taken a strong stand on this issue - insisting that girls of school age attend the local facilities, even to the point of holding parents accountable and liable to punishment for the non-attendance of their daughters" (Hart 2001, p. 32). Although the egalitarian rhetoric has not been followed completely in practice, a number of women were directly involved in combat, and there is anecdotal evidence of improved conditions for women in areas controlled by the Maoists, such as decreases in polygamy, domestic violence, and alcoholism (Lama-Tamang et al. 2003; Manchanda 2004; Geiser 2005; Aguirre and Pietropaoli 2008; Ariño 2008). The diffusion of the egalitarian Maoist ideology may also have increased the aspirations of young girls for their own education and the aspirations of parents for their daughters' education. One unintended aspect of the insurgency may have contributed to improving schooling outcomes, especially for girls: female labor 
force participation increased (Menon and Rodgers 2011), and there is evidence that when women have more control over household expenditure investments in children increase, especially for girls (e.g., Thomas 1990; Duflo 2003). Thus, in the case of Nepal, contrary to most episodes of violent conflict, the direction of the effect of the Maoist insurgency on schooling outcomes seems unclear a priori.

Nonetheless, one particular aspect of the Nepalese conflict is likely to have been unambiguously detrimental to education: the common insurgent practice of abducting civilians. Parents may have been deterred from sending their children to school out of fear that they would be abducted by the insurgents (Human Rights Watch 2004). Quoting figures from the Informal Sector Service Center (INSEC), UNESCO (2010) reports that between 2002 and 2006, the Maoists abducted 10,621 teachers and 21,998 students (p.8). According to additional data provided by INSEC, the total number of abductions by Maoist forces during the conflict amounted to more than 85,000. Although most abductees were seemingly returned unharmed after a few days of intensive indoctrination (Becker 2009; Macours 2011), a number of youths joined the Maoist fighters (in 2003, an estimated 30 percent of Maoist forces were aged 14-18 years). The indoctrination sessions held during abductions are likely to have played a part in their recruitment.

In this paper, I exploit differences in the intensity of violence experienced by individuals born at different times, surveyed at different times, and in different districts to shed light on the ways in which experiencing the insurgency at a young age affected educational outcomes.

Individual data from the 2001 and 2006 Demographic and Health Surveys (DHS) of Nepal are merged with detailed conflict data collected by INSEC, namely, the number of conflict fatalities, school destructions, and abductions by Maoists at the district level.

I find that overall conflict intensity, as measured by conflict casualties, was associated with an increase in female educational attainment, whereas abductions by Maoists, which often targeted school children, had the reverse effect. Male schooling also tended to increase more rapidly in areas where the fighting was more intense, but the estimates are smaller in magnitude and more sensitive to specification. Similar results are obtained across different identification strategies, and robustness checks indicate that these findings are not due to selective migration.

In the next section, I review the existing evidence on the impact of armed conflict on education outside Nepal with an emphasis on male-female differences. I then present the Nepalese conflict in section II, the data in section III, the empirical strategy in section IV, and the estimation results in section V. Section VI concludes. 


\section{Literature REVIEW}

A number of cross-country analyses suggest that political instability has large negative effects on growth but that recovery to equilibrium levels tends to be rapid (see Blattman and Miguel 2010, for a review). At the microeconomic level, the results of an emerging body of literature on the impact of war-related destruction or civil conflict on educational attainment show that violent conflict often leads to worse educational outcomes, but estimates vary substantially by conflict, gender, and educational level. Overall, girls in postprimary education appear to experience the worst effects.

In war-torn Germany and Austria, school-aged individuals exposed to war received fewer years of education (Ichino and Winter-Ebmer 2004; Akbulut-Yuksel 2009). In Guatemala, where the worst period of the Guatemalan civil war saw nearly 200,000 deaths, Chamarbagwala and Morán (2011) find that individuals who were of schooling age in departments that were more affected by the war completed fewer years of schooling and that this effect was much more marked for girls. In Bosnia and Herzegovina, Swee (2009) estimates that cohorts of children exposed to greater conflict intensity at the municipal level were less likely to complete secondary schooling, but primary schooling attainment was unaffected. Shemyakina (2011a) finds that girls (but not boys) who were of schooling age during the Tajik civil war were less likely to complete mandatory schooling in areas severely affected by conflict events. Rodriguez and Sanchez (2009) find that in Colombia, children aged 12 years and older who were exposed to more violence at the municipal level were more likely to drop out of school and enter the labor market. León (2012) finds that individuals who were born and raised in Peruvian districts that were more affected by conflict-related violence completed fewer years of education. Three recent papers, one by Akresh and de Walque (2008) and two by Annan, Blattman, and colleagues (Annan et al. 2009; Blattman and Annan 2010), illustrate the marked heterogeneity in findings on the impact of civil conflict across demographic groups and across conflicts. Akresh and de Walque (2008) estimate that cohorts of children exposed to the extremely violent Rwandan genocide, which killed 10 percent of the country's population, completed 18.3 percent fewer years of education. However, contrary to results from Guatemala, for example (Chamarbagwala and Morán 2011), they find that due to the nature of the conflict, nonpoor, male individuals were more negatively affected. Studying the effect of forced recruitment into the Ugandan Lord's Liberation Army, Annan et al. (2009) and Blattman and Annan (2010) find dramatically different effects for men and for women in the opposite direction of those obtained by, for example, Shemyakina (2011a) and Chamarbagwala and Morán (2011). The abducted men in their sample, who were abducted, on average, for just over 15 months, experienced much worse educational attainment and labor market outcomes as well as poorer psychological health (Blattman and Annan 2010). However, these authors find no such effects for female abductees, which they attribute to the lack of opportunities for women in general (Annan et al. 2009). 


\section{Conflict in NePal}

Nepal was an absolute monarchy until 1990. Despite multiparty democratic elections in 1991, a Maoist insurgency broke out in February 1996 in the Rolpa district and ended in 2006. The insurgency was initially concentrated in a few Communist strongholds in Western Nepal, but by the end of the war, conflict-related casualties were recorded in 73 of the 75 Nepalese districts. The Maoist presence varied from sporadic attacks to the organization of local governments and law courts. Over the course of the conflict, Maoists attacked government targets, such as army barracks, police posts, and local government buildings (Do and Iyer 2010). They were also reported to terrorize, loot, abduct, and physically assault civilians (Bohara et al. 2006). However, government security forces also killed civilians and were accused of using children for spying, torturing, displacing, and summarily convicting civilians (Bohara et al. 2006).

The principal objective of the insurgents was the creation of a constituent assembly to draft a new constitution. Other important stated aims were land redistribution and equality for all castes, language groups, and women.

A crucial moment in the conflict was the Maoists' abandonment of a shortlived cease fire in November 2001. From that point, the government's response intensified dramatically, involving the Royal Nepal Army and leading to an escalation of violence (see figure S1 in the supplemental appendix, available at http ://wber.oxfordjournals.org/). Building on opposition to King Gyanendra's authoritative reaction to the prolonged conflict, the Maoists joined forces with some of the country's major political parties, leading to the signing of a peace agreement in November 2006 and the creation of an interim government led by a power-sharing coalition that included the Maoists.

The intensity of conflict varied substantially across the districts of Nepal, as illustrated in figure 1, which depicts the distribution of districts between the three terciles of conflict deaths per 1,000 inhabitants. One specific characteristic of the Nepalese conflict that is likely to be particularly relevant for an analysis of educational outcomes is the insurgents' practice of abducting civilians, particularly school children, en masse for short periods of intensive indoctrination. As illustrated by figure S2, there is a positive correlation between the number of abductions by Maoists and the intensity of fighting as measured by conflict-related casualties, but the relationship is not systematic. Hence, it is possible to consider the effect of abductions over and above that of overall conflict intensity. ${ }^{2}$ Districts with the highest proportion of abductees among the population are found in the middle tercile, which may be due to a lesser need for indoctrination in Maoist strongholds. ${ }^{3}$ Districts in the top quartile of the distribution of

2. The correlation coefficient between total conflict deaths and abductions per 1,000 inhabitants is 0.14 .

3. Hutt (2005) also links abductions to the weakness of support for the Maoists: "The Maoists know that much of their support is hollow and based on fear. Maoist cadres have taken to mounting temporary abductions of large numbers of school teachers and students, who are taken to remote locations and subjected to political indoctrination sessions" (Hutt, 2005, p.86). 
Figure 1. Conflict Intensity across Districts of Nepal

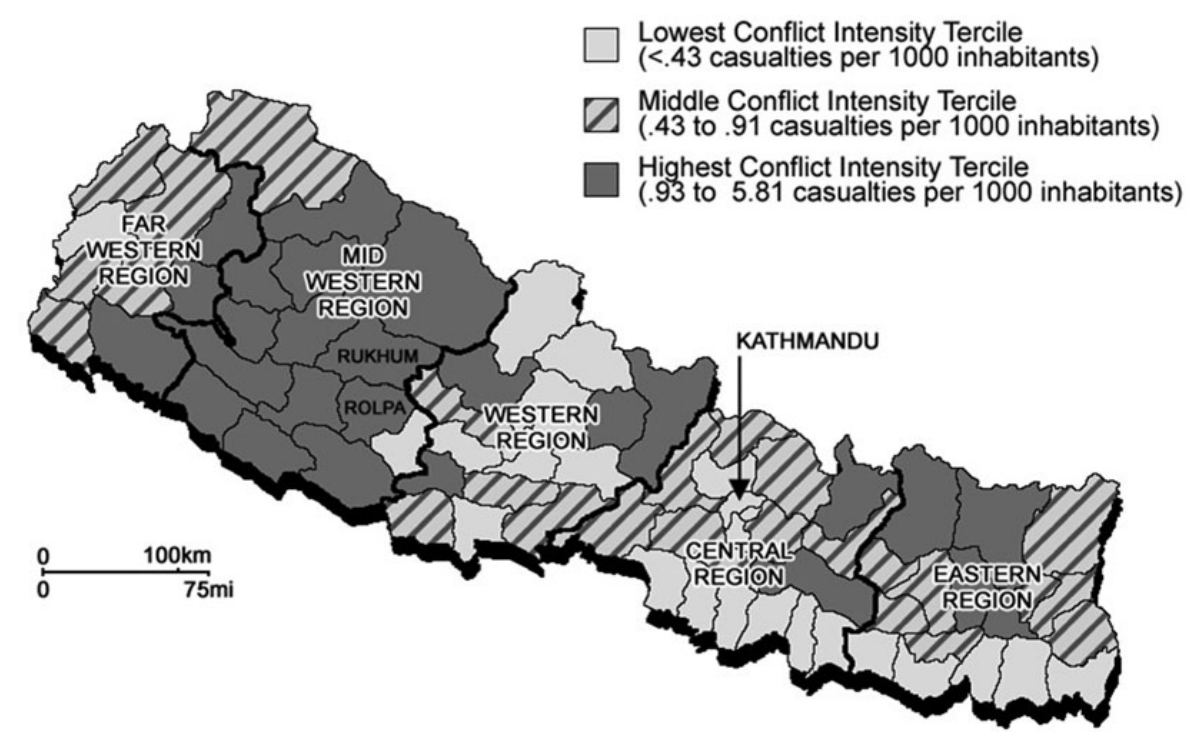

Notes: Author's calculations are based on casualties recorded in INSEC (2009) and district population figures from the 1991 population census (Central Bureau of Statistics, 2009). District terciles are defined by the distribution of total district casualties per 1,000 inhabitants.

abductions per 1,000 inhabitants that are not also in the top quartile of the distribution of casualties per 1,000 inhabitants tend to be found at the far western or eastern borders, close to districts characterized by intense fighting (i.e., numerous casualties).

Several arguments have been advanced to explain the district variation in the intensity of the insurgency, including geography (Murshed and Gates 2005; Bohara et al. 2006; Do and Iyer 2010), poverty (Murshed and Gates 2004; Do and Iyer 2010), a lack of political participation (Bohara et al. 2006), and intergroup inequality (Murshed and Gates 2005; Macours 2011). Determinants of district conflict intensity are therefore likely to be correlated with the explained variables of interest, which could give rise to omitted variable bias. As long as the omitted variables in question are constant over time, the inclusion of district fixed effects will suffice to remove any bias. If there are time-varying omitted variables correlated with both conflict intensity and the explained variables of interest, the inclusion of district fixed effects will not remove all potential biases, and additional steps must be taken to shed light on the causal impact of the insurgency. In section IV, I test for the presence of such time-varying omitted variables and discuss how I address potential threats to identification.

Despite the civil conflict, Nepal has experienced steady growth in real gross GDP (5 percent per year between 1995/96 and 2003/04), an additional increase 
in disposable income due to substantial flows of remittances from abroad (representing 12.4 percent of the GDP), a steady decrease in poverty over the period (from 42 percent in 1995/96 to 31 percent in 2003/04), and an improvement in human development indicators, such as primary school enrollment (up from 57 percent to 73 percent) and child mortality, which decreased by 5 percent per year (World Bank 2005; Macours 2011).

However, the positive outlook for Nepal as a whole may mask unequal progress due to heterogeneous conflict intensity across districts. Indeed, national trends may hide a slower decrease in poverty, or even an increase in poverty, in more conflict-affected areas. In this paper, I exploit variation in the intensity of exposure to violent conflict by birth cohort, survey year, and district to investigate differential changes in primary educational attainment and completed years of education across districts that experienced varying degrees of violence.

\section{DATA}

DHS have been conducted in a number of developing countries as part of the Measure DHS project, a reputable USAID-funded project. The second and third DHS in Nepal were conducted in 2001 and 2006, respectively, and are nationally representative repeated cross-sections. The timing of these surveys is particularly useful because the surveys either preceded or followed the bulk of the fighting. ${ }^{4}$

For each DHS, a household survey collected the usual individual demographic and education data as well as household-level socioeconomic information. More detailed information was then collected from all women and a subset of men of reproductive age (if ever married, in the case of the 2001 survey). The data used in this analysis come from the household survey as well as migration information from the detailed interviews with women in the 2006 DHS. ${ }^{5}$

Summary statistics by district conflict intensity and specification subsample can be found in table $\mathrm{S} 1$.

The data used to measure conflict intensity are taken from electronic files provided by INSEC, an independent, well-regarded human rights NGO based in Kathmandu with reporters in each of the 75 Nepalese districts who monitor human rights violations. The INSEC data files contain the number of conflict-related deaths per month per district of Nepal between February 1996 and December 2006 as well as the total number of school destructions and abductions by Maoists at the district level, which are used to construct most measures of exposure to conflict used in this paper. Data from INSEC have been extensively used in the media, international agencies, and government reports and in a number of academic studies, including those by Bohara et al. (2006) and Do and Iyer (2010). However, conflict deaths and school destructions are easier

4. In 2001, six out of 257 sampling units had to be dropped from the sample for security reasons (Ministry of Health et al., 2002, p.6).

5. In the 2001 survey, children listed on the household roster cannot be matched to their mothers. 
to monitor than abductions, and there are some surprising figures in the abduction data provided by INSEC, such as only 284 abductions by Maoists in Rolpa during the entire conflict. A degree of measurement error is likely to affect any conflict event data. If uncorrelated with the actual number of conflict events, this classical measurement error would lead to attenuation bias. However, the measurement error would have to be both inversely related to the true number of conflict events and very severe for it to lead to a reversal of the sign of the estimated effect of conflict. Such a result appears implausible given the degree of consensus on INSEC conflict data. Furthermore, findings using the number of casualties are consistent with the simple difference-in-difference calculations in table 1 , in which the conflict event counts are collapsed into binary indicators. These are more blunt indicators of conflict intensity, but they are also less prone to measurement error.

In addition, this study uses two indicators of Maoist control over a given district by 2003 based on classifications reported by Hattlebak (2007). I consider, in turn, two alternative definitions of Maoist control. I first categorize as under Maoist control any district that is categorized as such by both Maoists and the government (Definition 1). I then apply what Hattlebak (2007) considers a more reliable classification, the government classification (Definition 2).

\section{Empirical Strategy}

I exploit the fact that surveyed individuals have been exposed to varying degrees of conflict intensity according to their district of residence, year of birth, and whether they were surveyed in 2001 or in 2006.

The baseline estimation strategy is similar to that in much of the literature estimating the impact of civil conflict on individual outcomes reviewed in section I. The strategy exploits differences in exposure to conflict by birth year cohort and district of residence for individuals surveyed at the end of the conflict in 2006.

To check the robustness of the baseline results, I use a second identification strategy in which the source of identification is the change in the intensity of conflict within the district between 2001 and 2006, just before and just after the escalation of the conflict. By 2006, individuals born in 1991 and 1996, for example, would have been exposed to the same total amount of conflict before or during their schooling careers (albeit at different times in their lives). Hence, a comparison of the schooling outcomes of individuals born in 1991 and 1996 in the 2006 DHS would not be particularly informative. However, individuals born in 1991 who were observed at age 10 years in the 2001 survey experienced much less conflict by the time their education data were collected in 2001 than individuals born in 1996 and observed at age 10 years in the 2006 survey. Therefore, comparing their education outcomes at age 10 years is informative. ${ }^{6}$ This second

6. The variation in exposure between surveys also varies substantially between districts. For instance, in Mahottari, there were 0.14 additional deaths per 1,000 inhabitants between the two DHS, whereas in Jumla, there were close to three additional deaths per 1,000 inhabitants during the same period. 
approach allows me to use variation in conflict intensity over time that would be discarded in the traditional approach. In addition, the second approach provides the opportunity for useful checks of the robustness of my findings to potential migration and mortality biases.

I consider two outcome variables: a binary indicator for primary schooling completion and the number of years of education completed. Less than 45 percent (20 percent) of the male (female) adult population surveyed in the 2006 Nepal DHS had completed primary education, so primary schooling completion is a relevant cutoff in the present context. Given the recent occurrence of the conflict, a focus on primary education also has an advantage in that many individuals whose primary schooling careers coincided with the conflict period are old enough to have completed their primary education; hence, their long-term primary schooling outcomes are observed. Finally, given the high prevalence of voluntary migration in Nepal, it is important to test the robustness of my findings to migration bias. I do this by comparing the schooling attainment of children under 15 years of age surveyed in 2001 and 2006 in a given district. This age group is appropriate as long as I focus on primary education. As of 2004, 97 percent of Nepali migrants were men aged 15-44 years who typically left their wives and children behind (Lokshin and Glinskaya 2009). By focusing on children under 15 at the time of the survey, the individual is thus both unlikely to have migrated himself and unlikely to have accompanied a migrant parent. The DHS did not collect detailed migration data, but it does provide data on the date of arrival at the current location for women of reproductive age. Before the age of 15 years, the overwhelming majority of children are still living with their mothers; hence, I can further test the robustness of my findings for migration bias by restricting the sample to children whose mothers had not migrated since the beginning of the conflict.

\section{Specification 1: Exploiting Differences in Exposure to Conflict between Birth Year Cohorts within Districts}

Similar to previous studies on the impact of conflict on educational attainment, I first use data from the postconflict DHS (2006) and exploit variations in exposure to conflict by birth year cohort and district. In its simplest form, the estimating equation can be written as follows:

$$
\mathrm{EDUC}_{i j}^{t}=\delta_{j}+\alpha_{t}+\beta \mathrm{TOTCONF}_{j}^{t}+\varepsilon_{i j}^{t}
$$

where $E D U C_{i j}^{t}$ is, in turn, a dummy variable equal to one if individual $i$ in district $j$ born in year $t$ has completed primary education and zero otherwise or the number of years of education completed by this individual; $\delta_{j}$ represents district fixed effects; $\alpha_{t}$ represents birth year dummies; and TOTCONF ${ }_{j}^{t}$ is the interaction between a dummy equal to one when the individual belongs to the treated cohort and the number of conflict casualties (per 1,000 inhabitants) in district $j$ 
during 1996-2006. In the baseline regressions, I define the treated cohort as those aged 5 to 9 years at the beginning of the conflict in 1996, whereas the control cohort includes individuals aged 16 to 19 years at the beginning of the conflict. This choice is discussed in the preliminary analysis at the end of this section.

Under the assumption that there is no correlation between the number of district casualties and unobserved factors varying with district and birth cohort, $\beta$ is the causal effect of a one-unit increase in TOTCONF${ }_{j}^{t}$ on the primary completion rate or on the number of years of education completed by exposed cohorts. A one-unit increase in TOTCONF T $_{j}$ roughly corresponds to one standard deviation in the district-level distribution of casualties (0.98). Another way of appraising the magnitude of $\beta$ is to consider a one-unit increase in $\operatorname{TOTCONF}_{j}^{t}$ as a move from the district with the least conflict to the 53rd district (out of 75) in order of conflict intensity or from the 53rd district to the 69th district in order of conflict intensity - a very large increase in conflict intensity.

There are five "developmental regions" in Nepal, which are relatively homogeneous in terms of their level of development (see figure 1). In equation (1), I implicitly restrict birth cohort effects $\left(\alpha_{t}\right)$ to be identical across development regions. To reduce the potential for unobserved cohort-district varying factors to bias the estimate of the effect of conflict exposure, in the main set of results, I report estimates of equation $(1 R)$ in which the birth year intercepts are allowed to vary by development region $\left(\alpha_{t}^{R}\right){ }^{7}$ Here, the effect of conflict is identified by using the difference in exposure to conflict by district and birth year cohort, net of birth year trends common to all districts within a given development region:

$$
\mathrm{EDUC}_{i j}^{t}=\delta_{j}+\alpha_{t}^{R}+\beta \mathrm{TOTCONF}_{j}^{t}+\varepsilon_{i j}^{t}
$$

In addition, I estimate variants of equation (1) in which I add regressors capturing specific aspects of the conflict that are likely to have affected schooling outcomes, namely, the number of school destructions and abductions by Maoist forces (per 1,000 inhabitants) during the conflict. I also consider whether Maoist control over the district had an effect on primary attainment by estimating variants of equation (1) in which I replace TOTCONF ${ }_{j}^{t}$ with an indicator variable that switches on when the district was under Maoist control at the height of the conflict.

It would be desirable to control for the socioeconomic status of the household in which an individual was raised. However, household characteristics are not included as regressors in this specification because these are only observed at the time of the survey in 2006, 10 years after the beginning of exposure to conflict, and may therefore be caused by the conflict. In addition, at the time of the survey, individuals in the control group were 25-28 years old, and members of

7. Note that region dummies are subsumed under the district fixed effects, but the interactions between regions and birth year dummies are not. 
the treated group were 14-18 years old. Therefore, it is difficult to imagine household characteristics that would not depend on the individual's education level at the time of the survey. In the second identification strategy described below, I observe school-aged children in their household; hence, I can control for household characteristics.

\section{Specification 2: Comparison of Outcomes in 2001 and 2006 for a Given Age at Interview}

In equation (1), I only use data from the postconflict DHS (2006) and exploit variations in exposure to conflict according to birth year cohort and district. However, there is a comparable survey for 2001, just before the conflict escalated, which allows me to estimate the impact of the conflict using an alternative identification strategy based on variation in conflict exposure by survey date and district. The idea is to exploit the fact that a child aged, for example, 10 years in 2001 will have experienced much less conflict during his lifetime than another child aged 10 years in 2006 in the same district, and the difference in conflict exposure between these two children will also vary across districts. Finding results similar to those obtained using the traditional identification strategy in equation (1) would bolster confidence in the reliability of my estimates. More specifically, I estimate the following:

$$
\begin{aligned}
\operatorname{EDUC}_{i j}^{s} & =\theta_{j}+\lambda_{s}+\gamma \operatorname{CONFEXP}_{i j}^{s}+X_{i j}^{s^{\prime}} \varphi+\mu_{i j}^{s} \\
s & =2001,2006 \\
\text { CONFEXP }_{i j}^{s} & =\sum_{y=b i r t h y_{i}}^{s} \operatorname{CONF}_{j y}
\end{aligned}
$$

where $E D U C_{i j}^{s}$ is the primary education completion dummy or the number of completed years of education of individual $i$ in district $j$ observed in survey year $s, \theta_{j}$ represents district fixed effects, $\lambda_{s}$ is a survey dummy equal to one for DHS 2006 and zero for DHS 2001, CONF $F_{j y}$ is the number of conflict deaths per 1,000 inhabitants that occurred in district $j$ in year $y$, and CONFEXP $P_{i j}^{s}$ is the number of conflict deaths per 1,000 inhabitants in district $j$ that occurred between the individual's birth year and survey year $s$ in which the individual is interviewed, which I calculate from yearly district death counts. When $E D U C_{i j}^{s}$ is the primary education indicator, the sample comprises children aged 10-18 years, who may have completed primary education at the time of the survey. When $E D U C_{i j}^{s}$ is the number of years of education completed, the sample comprises children aged 514 years, who are of primary school age at the time of the survey. Under the assumption that there is no correlation between the cumulative number of district casualties between 1996 and year $s$ and unobserved district-survey-varying factors, $\gamma$ is the causal effect of a one-unit increase in CONFEXP $P_{i j}^{s}$ on the rate of primary schooling completion (the number of years of education completed) by 
the 10- to 18-year-old (5- to 14-year old) group. The magnitude of $\gamma$ can be directly compared to that of $\beta$ because both TOTCONF ${ }_{j}^{t}$ and CONFEXP ${ }_{i j}^{s}$ are expressed in district casualties per 1,000 inhabitants.

$X_{i j}^{s}$ is a set of controls that contains age at interview dummies and their interaction with the survey dummy in all specifications, thus allowing the educational attainment of each age group to vary independently between the two surveys. ${ }^{8}$ These covariates are included to control for potential differences in the 20012006 change in the district-level age composition of the 10- to 18-year-old or 5to 14-year-old group that, if correlated with conflict intensity, could bias the results. In some variants, $X_{i j}^{s}$ also includes household characteristics at the time of the survey (rural location and education of the household head). These characteristics are only measured at the time of the survey and could potentially be caused by past conflict. However, finding similar results when these observable household characteristics are included would suggest that potential changes in the composition of households due to mortality or migration do not drive my findings.

To further reduce the potential for unobserved time-varying factors to bias the estimate of the effect of conflict exposure, in the main set of results, I report estimates of equation $(2 R)$ in which the coefficients of the survey dummy, the age at survey intercepts, and their interactions are allowed to vary by development region. Here, the effect of conflict exposure is identified using the within-district change in conflict exposure at age $x$ between 2001 and 2006, net of 2001-2006 changes in educational attainment at age $x$ common to all districts in a given development region:

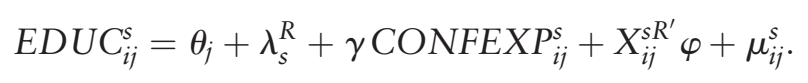

This second identification strategy has three important advantages compared to the traditional approach based on variation in exposure by birth cohort and district for individuals observed at a single point in time. First, it has the advantage of comparing cohorts that are born only five years apart but have experienced very different degrees of conflict (i.e., a 10-year-old in 2001 in district $j$ was exposed to much less conflict than a 10-year-old in 2006 in district $j$ but was born only five years earlier), which reduces concerns regarding potential confounders, including differential migration patterns. Second, when the sample is restricted to children aged 14 years and under, the concern regarding selection bias due to voluntary migration decreases because most migrants are men aged 15-44 years, who typically leave their wives and children behind (Lokshin and Glinskaya 2009). Third, I can further test the robustness of my findings to

8. When estimating equation (2) without any of the controls included, $\gamma$ is positive and statistically significant for both females and males in the completed years of education regression and positive and statistically significant for females only in the primary education completion regression (full results are available upon request). 
migration bias by excluding from the sample children surveyed in 2006 whose mothers moved to their current location after $1996 .^{9}$

All specifications are estimated using linear district fixed-effects panel data models. All models allow for error terms to be correlated in an arbitrary fashion within a district to avoid overrejection of the null hypothesis of zero treatment effect due to serial correlation, following Bertrand et al. (2004).

\section{Preliminary Analysis}

An inspection of the data shows that although the legally mandated age for beginning schooling is six years old and there are five years of primary schooling, a sizeable proportion of children are enrolled in primary school before age six (70.1 percent at five years) and until age 14 (16.1 percent) in the 2006 DHS, with numbers subsequently decreasing sharply (7.9 percent at 15 years and 2.85 percent at 16 years). ${ }^{10}$ Therefore, an analysis of the long-term effect of conflict on primary schooling completion should consider children aged at least 14 years at the time of the survey, and control cohorts should have been at least 15 years at the beginning of the conflict (and preferably slightly older). When estimating variants of equation (1), I therefore define the treated cohort as comprising individuals aged five to nine years at the beginning of the conflict in 1996, such that all treated cohorts are exposed to the conflict during most of their potential primary schooling careers and the youngest exposed cohort is observed at age 14 in the 2006 DHS. In the main regressions, the control cohorts include individuals aged 16 to 19 years at the beginning of the conflict-that is, individuals who were born too early to have their primary education affected by the conflict but are as close, and therefore as comparable, to the treated cohorts as possible. I also provide a robustness check in which the control group comprises individuals aged 18-25 years at the start of the conflict. In the baseline specification, I exclude cohorts aged 10 to 15 years in 1996 because the treatment status of these cohorts is less clear. Many of these individuals could have been enrolled in primary schooling during the conflict, but they were not exposed to conflict during most of their primary schooling careers (see figures S3a and S3b).

Panel A of table 1 illustrates the basic identification strategy used in the baseline specification. This panel shows the difference in the increase in primary schooling between cohorts exposed (row (1)) and not exposed (row (2)) to conflict during their primary schooling careers in districts experiencing abovemedian conflict casualties (columns (1) and (4)) compared to districts experiencing below-median conflict casualties (columns (2) and (5)). Women born too early to be affected by the conflict during their primary schooling years have a

9. The education data used in this paper come from the DHS household datasets. Information on date of arrival at the present location was only collected in individual interviews with women aged 15-49 years. The same exclusion could not be implemented for the 2001 DHS because individuals listed on the household roster cannot be matched to their mothers.

10. In the 2001 DHS, 44.4 percent of five-year-olds, 24.6 percent of 14 -year-olds, and 13.6 percent of 15 -year-olds were enrolled in primary schooling. 
Ta ble 1. Preliminary Difference-in-Difference Calculations, Completion of Primary Schooling

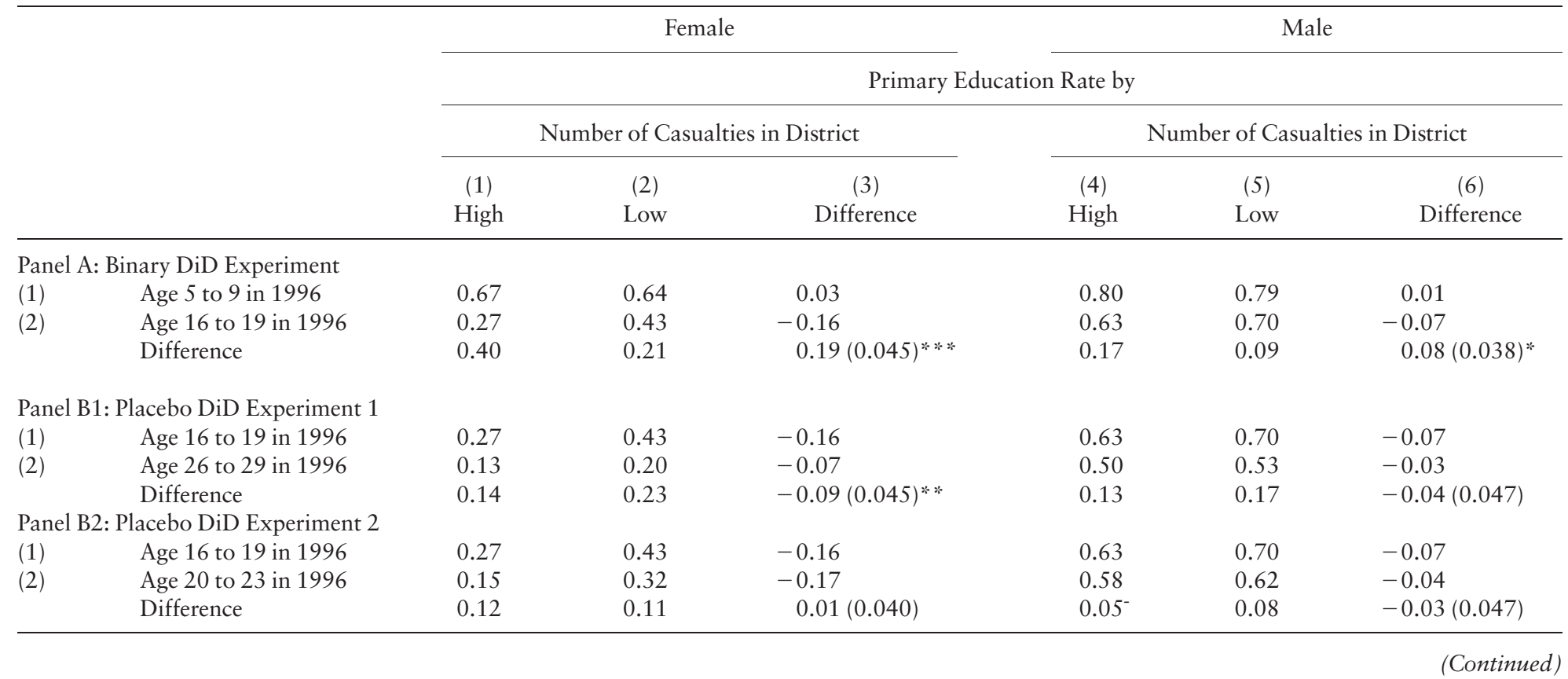




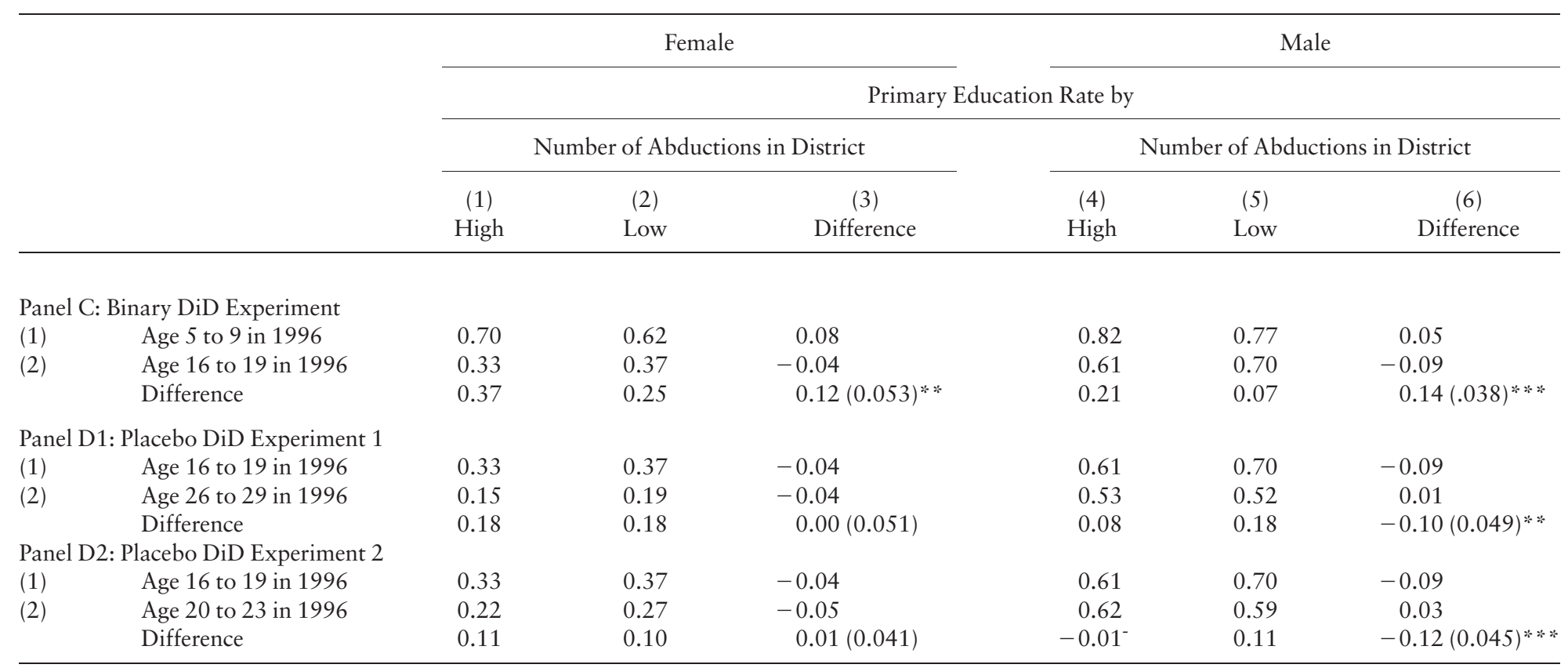

Notes: District casualties are expressed per 1,000 inhabitants. "High" and "Low" refer to above-median or below-median district totals per 1,000 inhabitants. Standard errors clustered at the district level are in parentheses. All first differences (i.e., row (1) - row (2) for a given conflict category) are statistically significant, except for values marked with ${ }^{-}$. DiD indicates difference-in-difference. ${ }^{*} \mathrm{p}<0.10, * \mathrm{p}<0.05, * * \mathrm{p}<0.01$.

Source: INSEC 2009, Central Bureau of Statistics 2009. Education data are based on Nepal DHS 2006. 
much lower rate of primary schooling in high-conflict districts compared to women in low-conflict districts. In contrast, primary schooling completion is slightly higher in high-conflict districts compared to low-conflict districts among the cohort of women who were entering primary school around the beginning of the conflict, resulting in an additional increase in female primary schooling of 19 percentage points between the two cohorts in high-conflict areas compared to low-conflict areas. A qualitatively similar but less dramatic effect is observed among men.

To shed light on the direction of the potential biases due to differential preconflict trends, I conduct several control or "placebo" experiments in which conflict exposure is artificially assigned to cohorts who were too old to be affected by the conflict. In panel B1, I compare the change in primary schooling attainment between cohorts aged 16-19 years and cohorts aged $26-29$ years at the beginning of the conflict in above-median versus below-median conflict intensity districts. The difference-in-difference is negative, and for females, it is statistically significant. This finding indicates that rates of primary schooling completion were improving more slowly in areas where more conflict occurred in 19962006 when comparing cohorts that were potentially enrolled in primary school (i.e., aged 5-14 years) in the 1972-1984 period and cohorts that were potentially enrolled in the 1982-1994 period. If this trend had continued during the conflict period, the estimates presented in this paper would be a lower bound of the true effect of conflict; that is, the positive coefficient of the conflict variable would be an overly conservative estimate, especially for females.

The ideal placebo experiment would be based on the actual cohorts involved in the experiment of interest in the absence of conflict. Such a test is clearly not feasible. However, it is possible to conduct an additional placebo experiment based on cohorts born immediately before the period relevant to the experiment of interest to check for differences in trends as close as possible to the period of interest. The results of this additional placebo experiment comparing cohorts aged 16-19 years at the beginning of the conflict with those aged 20-23 years are shown in panel B2. During this period immediately preceding the conflict, I cannot reject the hypothesis that the evolution of primary schooling was parallel in districts with above- and below-median conflict casualties for both males and females.

In panel $\mathrm{C}$, the experiment is conducted by replacing the below- and abovemedian casualty categories with below- and above-median Maoist abduction categories. The results in panel $\mathrm{C}$ show that primary schooling has progressed more rapidly in districts with above-median Maoist abductions. However, two-thirds of districts classified as high (low) conflict based on the median number of casualties are also classified as high (low) conflict based on the median number of abductions. Therefore, these simple two-by-two calculations may capture the effect of overall conflict intensity, the effect of Maoist abductions, or both. In the regressions that follow, I disentangle the effect of overall conflict intensity and Maoist abductions by including both conflict variables. 
Panels D1 and D2 show results for tests that replicate the placebo tests for panels B1 and B2, where the definition of high- and low-conflict districts based on above- and below-median conflict casualties is replaced with the definition based on above- and below-median district abductions. Females experienced similar preconflict primary education trends in high- and low-abduction districts. Male cohorts found in high-abduction districts experienced slower progress in preconflict primary education relative to low-abduction districts. If the same trends continued for cohorts considered in the experiment of interest, then the effect of exposure to Maoist abductions would tend to be biased downward for males (i.e., to be more negative) but not for females. On the contrary, in the regression analysis, I find that after controlling for district casualties, the education of females suffered from Maoist abductions, but that the education of males did not. Therefore, the difference in male trends observed in panels D1 and D2 does not drive my conclusions.

\section{RESULTS}

The preliminary analysis in section IV suggested that primary schooling completion rates tended to increase more rapidly during armed conflict in areas that experienced a high intensity of conflict, especially for girls. In tables 2 to 4, I present estimates of the impact of exposure to conflict on educational outcomes to determine whether this striking conclusion of the preliminary analysis is confirmed when using more detailed information on the intensity of conflict, controlling for unobserved heterogeneity between individual districts and between regions over time and using different identification strategies.

Table 2 reports findings on the impact of conflict exposure on primary schooling completion. The first two columns present estimates of the long-term effect of conflict intensity on primary schooling completion using the baseline specification (equation $(1 R))$. The last four columns indicate the robustness of these findings through comparison of the change in primary completion rates for the 10- to 18-year-old group for districts with varying degrees of conflict intensification between the 2001 and 2006 DHS (equation (2R)). The last two columns include controls for rural location and the educational attainment of the household head.

The results in the first column indicate that areas with more fighting witnessed a larger increase in female primary education attainment. Casting this result in terms of the distribution of conflict violence, an increase in violence of one standard deviation of the district-level distribution of casualties during the conflict (0.98 casualties per 1,000 inhabitants) increases female primary schooling attainment by 5.6 percentage points. This is roughly the effect of a move from the 5 th to the 75 th percentile of the district-level conflict distribution of total casualties. The sign and order of magnitude of this effect is confirmed when comparing cohorts born only five years apart but exposed to very different levels of conflict using equation (2R). Across all specifications in table 2, conflict exposure does 
TA B LE 2. Impact of Conflict Intensity Measured by Casualties on Primary Schooling Completion

\begin{tabular}{|c|c|c|c|c|c|c|}
\hline Explained Variable and Sample & $\begin{array}{l}(1) \\
\text { Primary } \\
\text { Education - } \\
\text { Female }\end{array}$ & $\begin{array}{l}(2) \\
\text { Primary } \\
\text { Education - } \\
\text { Male }\end{array}$ & $\begin{array}{l}\text { (3) } \\
\text { Primary Education - } \\
\text { Female 10-18 }\end{array}$ & $\begin{array}{c}(4) \\
\text { Primary } \\
\text { Education - Male } \\
10-18\end{array}$ & $\begin{array}{l}\qquad 5) \\
\text { Primary Education } \\
\text { - Female } 10-18\end{array}$ & $\begin{array}{l}\text { (6) } \\
\text { Primary Education } \\
\text { - Male 10-18 }\end{array}$ \\
\hline Specification & Eq. $(1 \mathrm{R})$ & Eq. $(1 \mathrm{R})$ & Eq. $(2 R)$ & Eq. $(2 R)$ & Eq. $(2 R)$ & Eq. $(2 R)$ \\
\hline $\begin{array}{l}=1 \text { if } 5-9 \text { in } 1996 \times \text { District } \\
\text { casualties during } 1996-2006 \\
(\text { TOTCONF }\end{array}$ & $\begin{array}{l}0.0555^{* *} \\
(0.0272)\end{array}$ & $\begin{array}{c}0.0241 \\
(0.0251)\end{array}$ & & & & \\
\hline $\begin{array}{l}\text { District casualties before survey } \\
(\text { CONFEXP } \\
=1 \text { if rural }\end{array}$ & & & $\begin{array}{l}0.0764^{*} \\
(0.0431)\end{array}$ & $\begin{array}{c}0.0036 \\
(0.0368)\end{array}$ & $\begin{array}{l}0.0811^{* *} \\
(0.0368) \\
-0.1094 * * \\
(0.0205)\end{array}$ & $\begin{array}{c}0.0094 \\
(0.0338) \\
-0.0622^{* * *} \\
(0.0154)\end{array}$ \\
\hline$=1$ if head has primary education & & & & & $\begin{array}{c}0.0543 * \cdots \\
(0.0133)\end{array}$ & $\begin{array}{c}0.0684^{* * *} \\
(0.0115)\end{array}$ \\
\hline$=1$ if head has secondary education & & & & & $\begin{array}{c}0.2127 * * * \\
(0.0120)\end{array}$ & $\begin{array}{c}0.2046 * * * \\
(0.0139)\end{array}$ \\
\hline$=1$ if head has higher education & & & & & $\begin{array}{c}0.3249 * * * \\
(0.0251)\end{array}$ & $\begin{array}{c}0.2597 * * * \\
(0.0253)\end{array}$ \\
\hline $\begin{array}{l}\text { Panel variable } \\
\text { Included dummies: }\end{array}$ & District & District & District & District & District & District \\
\hline Year of birth & Yes & Yes & No & No & No & No \\
\hline Region $\times$ Year of birth & Yes & Yes & No & No & No & No \\
\hline DHS 2006 & No & No & Yes & Yes & Yes & Yes \\
\hline
\end{tabular}


TABLE 2. Continued

\begin{tabular}{|c|c|c|c|c|c|c|}
\hline Explained Variable and Sample & $\begin{array}{c}(1) \\
\text { Primary } \\
\text { Education - } \\
\text { Female }\end{array}$ & $\begin{array}{c}(2) \\
\text { Primary } \\
\text { Education - } \\
\text { Male }\end{array}$ & $\begin{array}{l}\text { (3) } \\
\text { Primary Education - } \\
\text { Female } 10-18\end{array}$ & $\begin{array}{c}(4) \\
\text { Primary } \\
\text { Education - Male } \\
10-18\end{array}$ & $\begin{array}{l}\qquad 5) \\
\text { Primary Education } \\
\text { - Female } 10-18\end{array}$ & $\begin{array}{l}\text { (6) } \\
\text { Primary Education } \\
\text { - Male 10-18 }\end{array}$ \\
\hline Specification & Eq. $(1 \mathrm{R})$ & Eq. $(1 \mathrm{R})$ & Eq. $(2 R)$ & Eq. $(2 R)$ & Eq. (2R) & Eq. $(2 R)$ \\
\hline Age at interview & No & No & Yes & Yes & Yes & Yes \\
\hline Region $\times$ DHS 2006 & No & No & Yes & Yes & Yes & Yes \\
\hline DHS $2006 \times$ Age at interview & No & No & Yes & Yes & Yes & Yes \\
\hline Region $\times$ Age at interview & No & No & Yes & Yes & Yes & Yes \\
\hline $\begin{array}{l}\text { DHS } 2006 \times \text { Region } \times \text { Age } \\
\text { at interview }\end{array}$ & No & No & Yes & Yes & Yes & Yes \\
\hline Observations & 3,823 & 3,055 & 9,595 & 9,267 & 9,584 & 9,255 \\
\hline No. of clusters & 75 & 75 & $69^{a}$ & $69^{\mathrm{a}}$ & $69^{\mathrm{a}}$ & $69^{\mathrm{a}}$ \\
\hline R-squared & 0.1106 & 0.0368 & 0.2077 & 0.3021 & 0.2602 & 0.3372 \\
\hline $\mathrm{p}$ value male vs. female ${ }^{\mathrm{b}}$ & \multicolumn{2}{|c|}{0.345} & \multicolumn{2}{|c|}{0.074} & \multicolumn{2}{|c|}{0.044} \\
\hline
\end{tabular}

Notes: All specifications are estimated using the panel fixed-effects estimator and include a constant. District casualties are expressed per 1,000 inhabitants. Columns (1) and (2): Sample only includes individuals surveyed in the Nepal DHS 2006 and aged 5-9 years (treatment group) or 16-19 years (control group) at the beginning of the conflict in 1996. Columns (3) to (6): Sample only includes individuals surveyed in Nepal DHS 2001 or 2006 aged 10 to 18 years at the time of the survey. Standard errors clustered at the district level are in parentheses. ${ }^{*} p<0.10, * p<0.05, * * p<0.01$.

${ }^{a}$ DHS data collection was somewhat affected by the conflict in 2001. Hence, contrary to DHS 2006, four districts were not covered: Dolpa, Jajarkot, Rolpa, and Rukhum. The small districts of Manang and Mustang were not surveyed, but these districts did not experience any casualties during the conflict.

${ }^{b} \mathrm{p}$ value of an $\mathrm{F}$ test of equality between the reported treatment effects for males and females.

Source: INSEC 2009, Central Bureau of Statistics 2009, Nepal DHS 2001, and Nepal DHS 2006. 
TA B LE 3. Impact of Alternative Conflict Variables on Primary Schooling Completion

\begin{tabular}{|c|c|c|c|c|c|c|c|c|}
\hline & $\begin{array}{c}(1) \\
\text { School } \\
\text { Destructions } \\
\text { Female }\end{array}$ & $\begin{array}{c}(2) \\
\text { School } \\
\text { Destructions } \\
\text { Male }\end{array}$ & $\begin{array}{l}\text { (3) } \\
\text { Maoist } \\
\text { Abductions } \\
\text { Female }\end{array}$ & $\begin{array}{c}(4) \\
\text { Maoist } \\
\text { Abductions } \\
\text { Male }\end{array}$ & $\begin{array}{l}(5) \\
\text { Maoist Control } \\
\text { Female - } \\
\text { Definition } 1\end{array}$ & $\begin{array}{c}(6) \\
\text { Maoist Control } \\
\text { Male - } \\
\text { Definition } 1\end{array}$ & $\begin{array}{c}(7) \\
\text { Maoist Control } \\
\text { Female - } \\
\text { Definition } 2\end{array}$ & $\begin{array}{c}(8) \\
\text { Maoist Control } \\
\text { Male - } \\
\text { Definition 2 }\end{array}$ \\
\hline Explained Variable & $\begin{array}{l}\text { Primary } \\
\text { Education }\end{array}$ & $\begin{array}{l}\text { Primary } \\
\text { Education }\end{array}$ & $\begin{array}{l}\text { Primary } \\
\text { Education }\end{array}$ & $\begin{array}{l}\text { Primary } \\
\text { Education }\end{array}$ & $\begin{array}{l}\text { Primary } \\
\text { Education }\end{array}$ & $\begin{array}{l}\text { Primary } \\
\text { Education }\end{array}$ & $\begin{array}{l}\text { Primary } \\
\text { Education }\end{array}$ & $\begin{array}{l}\text { Primary } \\
\text { Education }\end{array}$ \\
\hline Specification & Eq. (1R) & Eq. (1 R) & Eq. (1 R) & Eq. (1R) & Eq. (1R) & Eq. (1R) & Eq. (1R) & Eq. (1R) \\
\hline $\begin{aligned} &= 1 \text { if } 5-9 \text { in } \\
& 1996 \times \text { District } \\
& \text { casualties during } \\
& 1996-2006 \\
&(\text { TOTCONF } \\
& \text { TOT) }\end{aligned}$ & $\begin{array}{l}0.0539^{*} \\
(0.0302)\end{array}$ & $\begin{array}{c}0.0301 \\
(0.0291)\end{array}$ & $\begin{array}{c}0.0638 * * \\
(0.0275)\end{array}$ & $\begin{array}{c}0.0231 \\
(0.0259)\end{array}$ & & & & \\
\hline $\begin{aligned} &= 1 \text { if } 5-9 \text { in } \\
& 1996 \times \text { District } \\
& \text { schools destroyed } \\
& 2002-2006\end{aligned}$ & $\begin{array}{c}0.4176 \\
(3.1298)\end{array}$ & $\begin{array}{l}-1.7848 \\
(2.3395)\end{array}$ & & & & & & \\
\hline $\begin{aligned}= & 1 \text { if } 5-9 \text { in } \\
& 1996 \times \text { Maoist } \\
& \text { Abductions during } \\
& 1996-2006\end{aligned}$ & & & $\begin{array}{c}-0.0022^{* * *} \\
(0.0005)\end{array}$ & $\begin{array}{l}0.0002 \\
(0.0010)\end{array}$ & & & & \\
\hline $\begin{aligned}= & 1 \text { if } 5-9 \text { in } \\
& 1996 \times \text { District } \\
& \text { controlled by } \\
& \text { Maoists } \\
& (\text { Definition } 1)\end{aligned}$ & & & & & $\begin{array}{l}0.0916 \\
(0.0590)\end{array}$ & $\begin{array}{c}0.2009 * * * \\
(0.0529)\end{array}$ & & \\
\hline
\end{tabular}

(Continued) 
TABLE 3. Continued

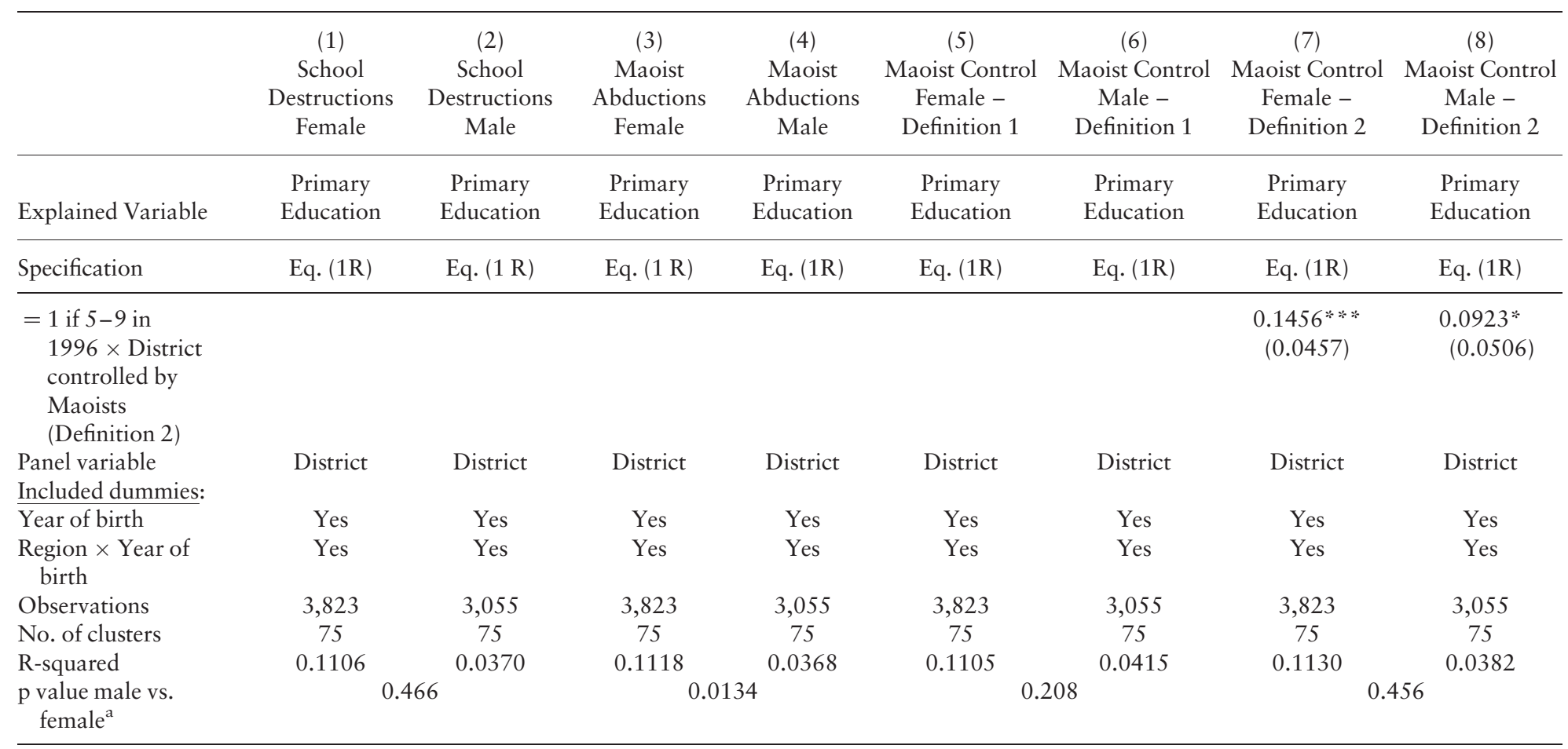

Notes: All specifications are estimated using the panel fixed-effects estimator and include a constant. School destructions and abductions by Maoists are expressed per 1,000 inhabitants. Sample only includes individuals surveyed in the Nepal DHS 2006 and aged 5-9 years (treatment group) or 16-19 years (control group) at the beginning of the conflict in 1996. Definition of a district controlled by Maoists based on matches between People's Army and government classifications as of 2003 (Definition 1) or government classification (Definition 2), according to Hattlebak (2007). Standard errors clustered at the district level are in parentheses. ${ }^{*} \mathrm{p}<0.10, * \mathrm{p}<0.05, * * \mathrm{p}<0.01$.

${ }^{\mathrm{a}} \mathrm{p}$ value of an $\mathrm{F}$ test of equality between the reported treatment effects for males and females.

Source: INSEC 2009, Central Bureau of Statistics 2009, Nepal DHS 2006, 
not appear to significantly affect male primary schooling completion, although the gender difference in the conflict effect is only statistically significant in columns (3) to (6).

These results are robust to including controls for household characteristics, suggesting that the results are not driven by a change in household composition due to, for example, selective mortality or migration (columns (5) and (6)). Table S2 presents specifications similar to those in table 2 but replaces the indicator for primary schooling completion with years of education completed. Similar results are obtained, indicating that an increase in violence of one standard deviation increases female educational attainment by 0.6 years.

Table S3 presents three different specifications to further check the robustness of the baseline results in the first two columns of table 2 to the following changes in specification: restricting birth year fixed effects to be identical across the five development regions of Nepal, changing the control cohort, and replacing the number of casualties with its natural logarithm. The results in table S3 confirm that primary education progressed more rapidly during the conflict in districts experiencing more casualties and that this effect was more robust across specifications for females.

Next, I investigate whether specific aspects of the conflict had different effects on primary schooling completion (table 3). First, I use INSEC data on the total number of school destructions per district to test whether these destructions had a negative effect on primary schooling completion despite the overall positive impact of the insurgency (columns (1) and (2)). For both genders, I find a statistically insignificant effect, which is likely because a district-level analysis lacks the power to identify the effect of school destructions. School destructions were a rare and isolated aspect of the conflict ${ }^{11}$ that could be expected to have had a large effect on schooling at a disaggregated level but not at the district level. Second, I use INSEC data on the total number of abductions by Maoists per district to test whether a larger number of abductions, often targeting school children, had an adverse effect on schooling. The results in columns (3) and (4) indicate that abductions had a negative effect on female primary schooling. An increase in the number of abductions (per 1,000 inhabitants) by one standard deviation of the district-level distribution (16.82) decreases female primary schooling attainment by 3.7 percentage points. In other words, the effect of a move from the 5 th to the 75 th percentile of the district-level distribution of total abductions yields a 1.6 percentage point decline in female primary completion. Third, I test whether primary schooling completion improved more in districts controlled by Maoists where the insurgents were better able to affect schooling provision according to their ideology (columns (5) to (8)). There is no clear-cut definition of insurgent control, with discrepancies between the classifications used by the People's Army and the government (Hatlebakk 2007). Therefore, I use two alternative classifications. The choice of definition affects the magnitude 
TA B LE 4. Impact of Conflict Intensity on Completed Years of Education, 5- to 14-year-olds

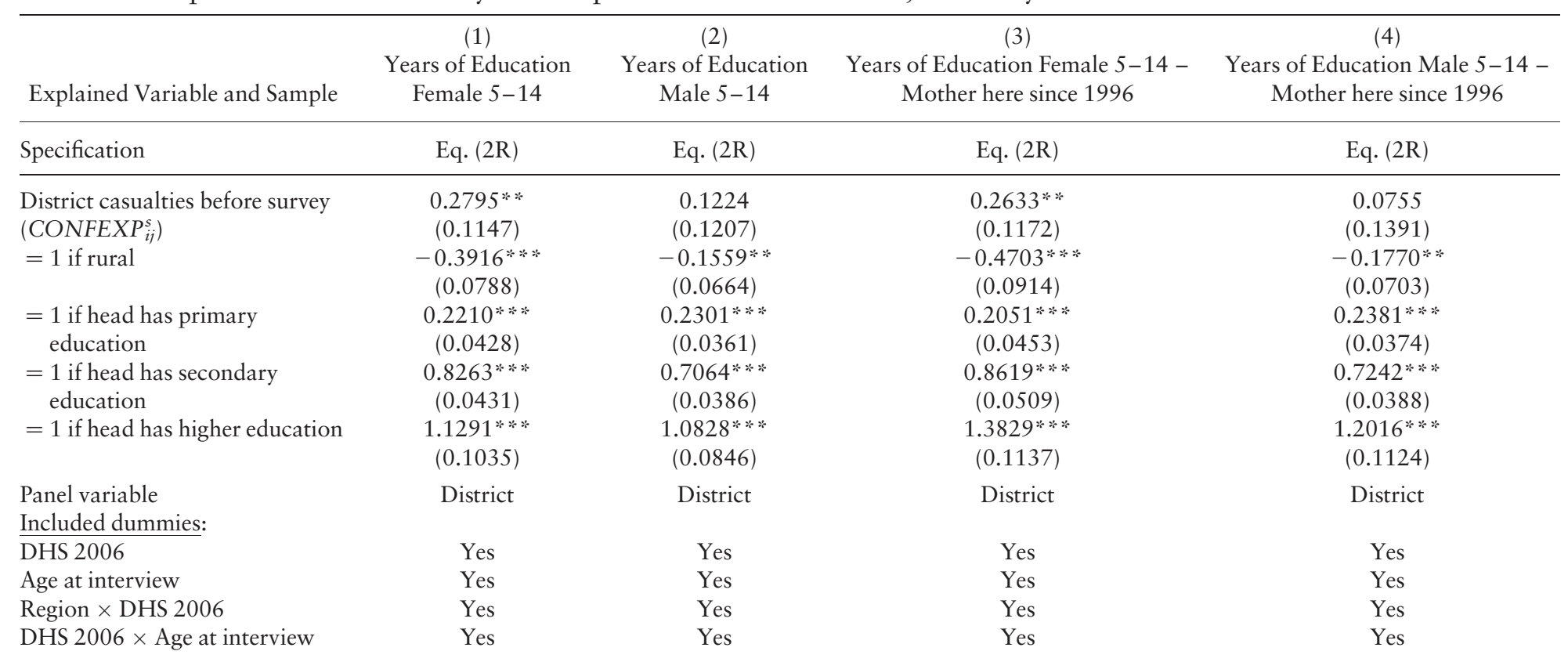


Region $\times$ Age at interview

DHS $2006 \times$ Region $\times$ Age at

interview

Observations

No. of clusters

R-Squared

p value male vs. female ${ }^{b}$

\begin{tabular}{|c|c|c|c|}
\hline Yes & Yes & Yes & Yes \\
\hline Yes & Yes & Yes & Yes \\
\hline 11,793 & 12,116 & 9,772 & 9,959 \\
\hline $69^{a}$ & $69^{a}$ & $69^{a}$ & $69^{a}$ \\
\hline 0.5062 & 0.6077 & 0.4909 & 0.5996 \\
\hline
\end{tabular}

Notes: All specifications are estimated using the panel fixed-effects estimator and include a constant. District casualties are expressed per 1,000 inhabitants. Sample only includes individuals surveyed in the Nepal DHS 2001 and 2006 and aged 5-14 years at the time of the survey. In columns (3) and (4), the 2006 sample is restricted to individuals whose mothers were interviewed individually and whose mothers reported having lived in their current place of residence as of 1996. The same exclusion could not be implemented for the 2001 DHS because individuals listed on the household roster cannot be matched to their mothers. Standard errors clustered at the district level are in parentheses. ${ }^{*} \mathrm{p}<0.10,{ }^{*} \mathrm{p}<0.05, * * \mathrm{p}<0.01$.

${ }^{a}$ DHS data collection was somewhat affected by the conflict in 2001. Hence, contrary to DHS 2006, four districts were not covered: Dolpa, Jajarkot, Rolpa, and Rukhum. The small districts of Manang and Mustang were not surveyed, but these districts did not experience any casualties during the conflict.

${ }^{\mathrm{b}} \mathrm{p}$ value of an $\mathrm{F}$ test of equality between the reported treatment effects for males and females.

Source: INSEC 2009, Central Bureau of Statistics 2009, Nepal DHS 2001, and Nepal DHS 2006. 
and significance of estimates, but the overall message is that primary schooling has tended to become more prevalent over time for both genders in areas controlled by the Maoists.

Tables S4 and S5 replicate the analysis in table 3 with birth year fixed effects restricted to be identical across development regions of Nepal (tables S4 and S5) and the control cohort replaced with individuals aged 18-24 years at the beginning of the conflict (table S5). The same conclusions apply as those drawn from the set of preferred results in table 3.

In table 4, I turn to the estimated effect of an increase in conflict intensity between 2001 and 2006 on completed years of education of children of primary schooling age (5-14 years) at the time they were surveyed (as per equation $(2 R)$ ).

Column (1) of table 4 indicates that an increase in casualties since birth by one standard deviation increases the completed years of education by just over onequarter of a year for girls aged 5 to 14 years in 2006 compared to girls from the same district who were the same age when surveyed in 2001, before the conflict escalated. For boys, the coefficient of interest is less than half the magnitude of that for girls and is significantly different from the estimated conflict effect for girls (at the 10 percent significance level). The estimates are very similar when restricting the 2006 sample to children whose mothers had not moved since 1996 (columns (3) and (4)), which confirms that changes in composition due to migration patterns are not driving these findings. In table S6, I repeat the analysis in table 4 but restrict the age intercepts and survey year dummy to be identical across Nepal's development regions. The results for the female sample are almost identical, but estimates for the male sample are now nearly as large as those for the female sample and are statistically significant. Echoing the findings for primary schooling completion, overall, these results confirm that primary education progressed more rapidly during the conflict in districts that experienced more casualties, and this effect is more robust across specifications for females.

In conclusion, the results presented in this section provide no support for the hypothesis that the Nepalese civil conflict had a negative effect on schooling overall. There is a robust positive effect of the intensity of the insurgency on female educational attainment, but there is less of an effect for male educational attainment. There is also evidence of a decrease in female primary schooling completion where insurgents were more prone to abductions, holding overall conflict intensity constant.

\section{CONCLUding REMARKS}

Despite experiencing a substantial civil conflict between 1996 and 2006, Nepal has surprisingly enjoyed one of the best periods in its history in terms of economic growth and poverty reduction. At present, however, little is known about whether this period of development at the aggregate level hides disparities at a more disaggregated level due to the wide variation in conflict intensity across the country. 
In this paper, I exploit variation in exposure to conflict by birth cohort, survey date, and district to estimate the impact of conflict intensity on schooling outcomes.

I find no support for the hypothesis that civil-conflict-related violence, as measured by the number of conflict casualties, had a negative effect on the quantity of schooling attained by children of either gender. On the contrary, there is robust evidence that female primary schooling attainment increased in districts that experienced more conflict deaths relative to districts with fewer conflict deaths. This result holds irrespective of whether one compares (within a given district) (i) the completion of primary education for cohorts exposed and not exposed to the conflict and observed at the end of the conflict or (ii) years of education completed by a given age for cohorts observed before (2001) and after (2006) a sharp escalation of the conflict and that were therefore exposed to very different degrees of conflict. It is also robust to a number of changes in specifications. In particular, robustness checks indicate that changes in household composition due to conflict-induced migration patterns do not drive this finding.

However, one aspect of the Nepalese civil conflict that is particularly relevant to schooling outcomes had adverse consequences on female primary schooling: the widespread insurgent practice of abducting civilians, many of whom were school children.

The findings reported in this paper echo the positive changes observed for Nepal as a whole during the conflict period in terms of economic growth, education, and child health. The present analysis shows that the progress in education observed at the country level does not hide a slower increase in districts where more fighting occurred, but the insurgent practice of abducting civilians adversely affected female educational outcomes. The estimates presented in this paper are in line with the existing qualitative literature on the Nepalese civil conflict, which consistently reports mixed conclusions with respect to the impact of the conflict on education and female empowerment (e.g., Hart 2001; Lama-Tamang 2003; Manchanda 2004; Pettigrew and Shneiderman 2004; Geiser 2005; Aguirre and Pietropaoli 2008; Ariño 2008; Falch 2010).

Education, particularly female educational attainment, appears to have benefited from the societal changes induced directly or indirectly by the insurgency more than it was adversely affected by the loss of income and other disruptions caused by the conflict. Data limitations prevent a more detailed analysis of the channels through which the conflict affected education beyond the distinction between the effect of conflict as a whole and that of abductions. However, potential mechanisms suggested by the existing anthropological and peace studies literature include Maoist efforts to remove barriers to schooling for all children from the lower castes and to reduce teacher absenteeism (e.g., Hart 2001; Lama-Tamang 2003), which could have benefited both male and female education; the Maoist influence in encouraging or coercing parents to send girls to school (Hart 2001); and the Maoists' effect on female empowerment. Although the exact figure is contested, a substantial share of the guerillas in the Maoist 
ranks was female. Many more females were involved in the Maoist movement without direct participation in combat, such as by disseminating propaganda (Lama-Tamang et al. 2003; Pettigrew and Shneiderman 2004), and even larger numbers may have been influenced by the Maoist discourse on gender equality. In addition, there is anecdotal evidence of an improvement in the condition of women in areas controlled by the Maoists, such as decreases in polygamy, domestic violence, and alcoholism, as well as greater support for women to divorce their husbands (Lama-Tamang et al. 2003; Manchanda 2004; Geiser 2005; Ariño 2008). Although the insurgents' rhetoric was often in contrast with their actual practice (Pettigrew and Shneiderman 2004), the presence of females in their ranks and the propaganda promoting female autonomy may have increased female bargaining power within the household as well as female aspirations. According to Hart (2001), "girls and women are strongly encouraged to gain an education and to participate in society generally and in activities connected to the 'People's War' in particular. This directly challenges their traditional role and apparently stimulates girls to consider leading lives beyond marriage and the home (Hart 2001, p.35)". Furthermore, an unintended consequence of the conflict has been that women have adopted roles typically reserved for men. Women's involvement in the labor market increased as a consequence (Menon and Rodgers 2011). The rise in female labor market participation may have increased returns to female schooling and motivated girls to obtain more education and parents to invest more in their daughters' education. Increased female earnings are also likely to improve the ability of mothers to influence the way household resources are spent. Moreover, there is evidence that when women have more control over household expenditures, such as because their own earnings make up a larger share of the household's income, investments in children increase; this is especially the case for girls (e.g., Thomas 1990; Duflo 2003), although this may not be the case in all contexts (Quisumbing and Maluccio 2003; Gitter and Barham 2008). Finally, the nature of the occupations of women outside the home also changed. In many areas, women were reported to take on leadership roles in local institutions, including schools (Pettigrew and Shneiderman 2004). This improvement in female representation in local institutions may have contributed to increased education, especially for girls.

Data limitations prevent rigorous tests of the role played by these different potential channels in explaining the finding that education, particularly female education, increased more in areas where the fighting was more intense. ${ }^{12}$ Future research aiming to disentangle the role of each of the channels through which the insurgency may have improved educational outcomes would be valuable.

An issue beyond the scope of this paper is the important question of the effect of civil conflict on the quality of education, which is potentially large (for a review, see Shemyakina and Valente 2011). Data limitations have thus far

12. See the appendix for some insights based on self-reported measures of female empowerment available in the DHS. 
precluded quantitative research on the impact of conflict on the quality of schooling, but there is growing evidence that cognitive skills, rather than completed years of education, matter for individual earnings and economic growth (e.g., Hanushek and Woessmann 2008). Therefore, even where the number of years of education completed is not adversely affected by civil conflict, such conflict may have deleterious effects on human capital if the quality of learning deteriorates.

From an international perspective, this paper contributes to unpacking the complexity that lies behind the generic term civil conflict. The idiosyncrasies of each conflict highlight the need for additional research on the impacts of different conflicts to shed light on the range of potential effects rather than a focus on extreme, but thankfully rare, instances.

From a policy perspective, the present findings call for measures that aim to protect school children and teachers from being directly targeted by combatants. As shown in this paper, even where primary education systems appear very resilient to surrounding violence, direct targeting of schools, however mild (e.g., brief abductions of pupils and teachers for indoctrination purposes), has adverse effects on schooling, especially for girls.

\section{REFERENCES}

Aguirre, D., and I. Pietropaoli. 2008. “Gender Equality, Development and Transitional Justice: The Case of Nepal.” The International Journal of Transitional Justice 2: 356-77.

Akbulut-Yuksel, M. 2009. "Children of War: The Long-run Effects of Large-scale Physical Destruction and Warfare on Children.” IZA Working Paper No.4407. Institute for the Study of Labor, Bonn, Germany.

Akresh, R., and D. de Walque. 2008. "Armed Conflict and Schooling: Evidence from the 1994 Rwandan Genocide.” World Bank Policy Research Paper No.4606. World Bank, Washington, DC.

Annan, J., C. Blattman, D. Mazurana, and K. Carlson. 2009. "Women and Girls at War: 'Wives', Mothers, and Fighters in the Lord's Resistance Army." HICN Working paper 63. Households in Conflict Network, Brighton, UK.

Ariño, M. V. 2008. "Nepal: A Gender View of the Armed Conflict and Peace Process." Quaderns de Construcció de Pau No.4. Escola de Cultura de Pau, Barcelona, Spain.

Armon, J., C. Berry, D. Duncan, R. Calder, S. Clapham, and M. Harvey. 2004. "Service Delivery in Difficult Environments: The Case of Nepal.” Department for International Development, Asia Policy Division.

Becker, J. 2009. "Child Recruitment in Burma, Sri Lanka, and Nepal.” In S. Gates, and S. Reich eds., Child Soldiers in the Age of Fractured States, 108-20. Pittsburg, PA: University of Pittsburg Press.

Bertrand, M., E. Duflo, and S. Mullainathan. 2004. "How Much Should We Trust Differences-in-Differences Estimates?” Quarterly Journal of Economics 1191: 249-75.

Blattman, C., and J. Annan. 2010. "The Consequences of Child Soldiering." Review of Economics and Statistics 92 (4): 882-98.

Blattman, C., and E. Miguel. 2010. “Civil War.” Journal of Economic Literature 48 (1): 3-57.

Bohara, A., N. Mitchell, and M. Nepal. 2006. "Opportunity, Democracy, and the Exchange of Political Violence: A Subnational Analysis of Conflict in Nepal.” Journal of Conflict Resolution 50 (1): $108-28$. 
Central Bureau of Statistics [Nepal]. 2009. Nepal Statistical Year book 2009. Central Bureau of Statistics, Kathmandu. http://cbs.gov.np/?page_id=1233, last accessed May 22, 2013.

Chamarbagwala, R., and H. E. Morán. 2011. “The Human Capital Consequences of Civil War: Evidence from Guatemala.” Journal of Development Economics 94: 41-61.

Collins, S. 2006. “Assessing the Health Implications of Nepal's Ceasefire.” Lancet 368: 907-8.

Devkota, B., and E. R. van Teijlingen. 2010. "Understand Effects of Armed Conflict on Health Outcomes: The case of Nepal." Conflict and Health 4: 20.

Do, Q-T., and L. Iyer. 2010. "Geography, Poverty and Conflict in Nepal.” Journal of Peace Research 47 (6): $735-48$.

Duflo, E. 2003. "Grandmothers and Granddaughters: Old-Age Pensions and Intrahousehold Allocation in South Africa.” World Bank Economic Review 17 (1): 1-25.

Falch, A. 2010. "Women's Political Participation and Influence in Post-Conflict Burundi and Nepal." Peace Research Institute Oslo Working Paper. Oslo, Norway.

Geiser, A. 2005. "Social Exclusion and Conflict Transformation in Nepal: Women, Dalit and Ethnic Groups.” Working Paper 5/2005. Swisspeace, Bern, Switzerland.

Gitter, S. R., and B. L. Barham 2008. "Women's Power, Conditional Cash Transfers, and Schooling in Nicaragua." World Bank Economic Review 22 (2): 271-90.

Hanushek, E. A., and L. Woessmann 2008. "The Role of Cognitive Skills in Economic Development." Journal of Economic Literature 46: 607-68.

Hart, J. 2001. "Conflict in Nepal and its Impact on Children.” A Discussion Document Prepared for UNICEF Regional Office South Asia, Refugee Studies Centre, Oxford.

Hatlebakk, M. 2007. “LSMS Data Quality in Maoist Influenced Areas of Nepal.” No 6, CMI Working Papers. CMI (Chr. Michelsen Institute), Bergen, Norway.

Human Rights Watch. 2004. "Between a Rock and a Hard Place: Civilians Struggle to Survive in Nepal's Civil War.” http:/www.hrw.org/en/reports/2004/10/06/between-rock-and-hard-place?print, last accessed May 20, 2013.

Hutt, M. 2004. "Nepal and Bhutan in 2004: Two Kings, Two Futures.” Asian Survey 45 (1): $83-87$.

Ichino, A., and R. Winter-Ebmer 2004. "The Long-Run Educational Cost of World War II.” Journal of Labor Economics 22 (1): 57-86.

INSEC. 2009. Electronic data files. Informal Sector Service, Kathmandu.

Lama-Tamang, M. S., S. M. Gurung, D. Swarnakar, and S. R. Magar 2003. "Social Change in Conflict Areas: Assessment Report." Prepared for UK Department for International Development (DFID) Nepal, Kathmandu.

León, G. 2012. "Civil Conflict and Human Capital Accumulation: The Long-Term Effects of Political Violence in Perú.” Journal of Human Resources 47 (4): 992-1022.

Lokshin, M. M., and E. Glinskaya 2009. "The Effect of Male Migration on Employment Patterns of Women in Nepal." World Bank Economic Review 23 (3): 481-507.

Macours, K. 2011. "Increasing Inequality and Civil Conflict in Nepal." Oxford Economic Papers 63 (1): $1-26$.

Manchanda, R. 2004. "Maoist Insurgency in Nepal. Radicalizing Gendered Narratives.” Cultural Dynamics 162 (3): 237-58.

Menon, N., and Y. Rodgers 2011. "War and Women's Work: Evidence from the Conflict in Nepal." World Bank Policy Research Working Paper No. 5745. World Bank, Washington, DC.

Ministry of Health [Nepal], New ERA, and ORC Macro. 2002. Nepal Demographic and Health Survey 2001. Calverton, Maryland: Family Health Division, Ministry of Health; New ERA; and ORC Macro.

Murshed, S. M., and S. Gates 2005. "Spatial-Horizontal Inequality and the Maoist Insurgency in Nepal." Review of Development Economics 9(1): 121-34.

Pettigrew, J., and S. Shneiderman 2004. "Women and the Maobaadi: Ideology and Agency in Nepal's Maoist Movement.” Himal South Asia 17 (1): 19-29. 
Quisumbing, A. R., and J. A. Maluccio 2003. "Resources at Marriage and Intrahousehold Allocation: Evidence from Bangladesh, Ethiopia, Indonesia, and South Africa." Oxford Bulletin of Economics and Statistics 65: 283-327.

Rodríguez, C., and F. Sánchez 2009. “Armed Conflict Exposure, Human Capital Investments and Child Labor: Evidence from Colombia.” HiCN Working Paper No. 68. Households in Conflict Network, Brighton, UK.

Shemyakina, O. 2011a. "The Effect of Armed Conflict on Accumulation of Schooling: Results from Tajikistan." Journal of Development Economics 95 (2): 186-200.

2011b. "Labor Market, Education and Armed Conflict in Tajikistan." World Bank Policy Research Working Paper No. 5738. World Bank, Washington, DC.

Shemyakina, O., and C. Valente 2011. "Education and Violent Conflict in South Asia: Challenges and Solutions." Background paper prepared for the World Bank Regional Study on "Improving the Quality of Learning in South Asia.” Mimeograph, University of Bristol, UK.

Swee, E. L. 2009. “On War and Schooling Attainment: The Case of Bosnia and Herzegovina.” HiCN Working Paper No. 57. Households in Conflict Network, Brighton, UK.

Thomas, D. 1990. “Intra-Household Resource Allocation: An Inferential Approach.” Journal of Human Resources 25 (4): 635-64.

UNESCO. 2010. Education under Attack. Paris, France: United Nations Educations Scientific and Cultural Organization.

USAID. 2007. Nepal - Humanitarian Assistance Fact Sheet No. 1, June. http://pdf.usaid.gov/pdf_docs/ PNADJ147.pdf, last accessed May 20, 2013.

Wallensteen, P., and M. Sollenberg 2001. “Armed Conflict 1989-2000.” Journal of Peace Research 38 (5): 629-44.

World Bank. 2005. "Nepal - Resilience amidst Conflict: An Assessment of Poverty in Nepal, 1995-96 and 2003-04.” Report No. 34834-NP. World Bank, Washington, DC. 